Referencia para citar este artículo: Carrillo-Urrego, A. (2018). Castigos en la crianza de los hijos e hijas: un estado de la cuestión. Revista Latinoamericana de Ciencias Sociales, Niñez y Juventud, 16(2), 719-740. doi:https://doi.org/10.11600/1692715x.16206

\title{
Castigos en la crianza de los hijos e hijas: un estado de la cuestión*
}

\author{
AbELARdo CARRILlo-URREGo** \\ Profesor Universidad del Tolima, Colombia.
}

\section{Artículo recibido en marzo 2 de 2017; artículo aceptado en mayo 10 de 2017 (Eds.)}

- Resumen (descriptivo): el objetivo de este trabajo es dar cuenta de los principales hallazgos de la investigación social reciente en torno a las formas y los tipos de violencia utilizados por las madres y los padres en la crianza de las niñas y los niños en el contexto mexicano. Hago la presentación de estos resultados teniendo en cuenta las estrategias metodológicas que han sido utilizadas en la investigación empírica. Revisar la bibliografía me permitió establecer que los principales recursos aceptados y utilizados por las madres y los padres para disciplinar a sus hijas e hijos continúa siendo la violencia en sus manifestaciones física, verbal y psicológica. Los estudios también han permitido identificar algunos factores de riesgo de la violencia ejercida con las niñas y los niños, vinculados a características demográficas, económicas y sociales de las madres y los padres.

Palabras clave: violencia infantil, crianza de los niños y niñas, violencia doméstica (Tesauro de Ciencias Sociales de la Unesco).

\section{Punishment in child rearing: the current state of this issue}

- Abstract (descriptive): The objective of this paper is to bring together the main findings of recent social research on the forms and types of violence used by parents in child rearing in the Mexican context. The results are organized based on the methodological strategies that have been used in different empirical studies. A literature review made it possible to establish that the main resources accepted and used by parents to discipline their children continue to be physical, verbal and psychological violence. Studies have also identified some risk factors for violence against children linked to the demographic, economic and social characteristics of their parents.

Key words: child abuse, child rearing, domestic violence (Unesco Social Science Thesaurus).

\section{Punição na criação dos filhos: um estado da matéria}

- Resumo (descritivo): o objetivo deste trabalho é explicar as principais descobertas da pesquisa social recente sobre as formas e tipos de violência que as mães e os pais usam na educação de meninas e meninos no contexto mexicano. A apresentação desses resultados é feita levando em consideração as estratégias metodológicas que foram utilizadas na pesquisa empírica. A revisão

Este artículo de investigación científica y tecnológica es producto del estudio titulado «Discursos y prácticas en torno a la aplicación de castigos disciplinarios en la crianza de las hijas y los hijos, en un sector popular de la Ciudad de México». Realicé la investigación entre septiembre de 2012 y diciembre de 2015. Fue financiada por el Consejo Nacional de Ciencia y Tecnología-Conacyt. El artículo pertenece a la gran área de conocimiento de las Ciencias Sociales, área de la Sociología y sub área de la Sociología.

** Sociólogo Universidad Nacional de Colombia, magíster en Ciencias Sociales de la Facultad Latinoamericana de Ciencias Sociales —Flacsosede académica México, Doctor en Ciencias Sociales, especialidad en Sociología, Centro de Estudios Sociológicos-El Colegio de México A. C. Integrante del Colectivo de investigación sobre conflictos de género — Ciscog— Universidad del Tolima. Orcid: 0000-0002-2557-1825. Correo electrónico: acarrillo@colmex.mx 
da literatura permitiu estabelecer que os principais recursos aceitos e utilizados pelas mães e pais para disciplinar suas filhas e filhos continuam a ser violência física, verbal e psicológica. Os estudos também identificaram alguns fatores de risco para a violência contra meninas e meninos ligados às características demográficas, econômicas e sociais das mães e dos pais.

Palavras-chave: violência contra crianças, criação dos filhos, violência doméstica (Thesaurus de Ciências Sociais da Unesco).

-1. Introducción. -2. Estudios realizados desde un enfoque cualitativo. -3. Estudios realizados desde un enfoque cuantitativo. -4. Estudios realizados desde un enfoque que integra métodos cualitativos y cuantitativos. $\mathbf{- 5}$. Conclusiones. -Lista de referencias.

\section{Introducción}

Pese a que desde tiempos inmemoriales se ha hecho padecer a las niñas y niños diversas formas de violencia, el interés público hacia el maltrato infantil era muy escaso antes de 1960. Tal como plantea Azaola (2006)

(...) no fue sino hasta 1962, cuando el doctor Kempe y sus colegas publicaron en Journal of the American Medical Association su trabajo acerca del síndrome del niño golpeado, que se inició la preocupación moderna por el abuso y la negligencia hacia las niñas y los niños, la cual ha crecido y se ha difundido entre todos los países durante las últimas cuatro décadas. (Gelles, 2001)

Posteriormente, desde diversas disciplinas se han efectuado estudios que han permitido complementar los hallazgos médicos y ofrecer una visión integral del problema (Azaola, 2006). No obstante las limitaciones que los datos disponibles puedan tener, la información existente sobre el tema muestra un panorama preocupante (ver Recuadro 1).

\section{Recuadro 1. Datos para caracterizar las dimensiones del problema}

Pese a la imposibilidad de realizar un estudio pormenorizado de la situación de violencia contra las niñas y los niños en el mundo y en la región, es necesario - al menos - mencionar algunos de los principales indicadores respecto al tema. Así, de acuerdo con un informe de Unicef (www.unicef.org), que presenta los datos estadísticos más recientes sobre violencia contra las niñas y los niños en 195 países,

(...) la violencia es una constante en la vida de las niñas y los niños del mundo de los más diversos orígenes y las más variadas circunstancias. La violencia interpersonal se manifiesta en muchas formas distintas - física, sexual y emocional-y tiene lugar en los entornos más variados, como el hogar, la escuela, la comunidad e Internet. De manera similar, la violencia contra las niñas y los niños proviene de una amplia gama de personas, entre ellas los integrantes de sus familias, parejas íntimas, maestros y vecinos, así como extraños y otros niños. Esa violencia no sólo les provoca a las niñas y los niños daño, dolor y humillación, sino que, puede causarles la muerte (Unicef, 2014, p. 2).

Solamente en 2012, el número de niñas y niños y adolescentes menores de 20 años que fueron víctimas de homicidio llegó a 95.000, lo que convirtió este delito en la principal causa prevenible de lesiones, heridas y muerte de menores. En su inmensa mayoría, esas víctimas (85 000) vivían en países de ingresos bajos y medios. A nivel mundial, la región de América Latina y el Caribe tienen la proporción más alta de víctimas de homicidio de menores de 25 
años (25 400)ํ. En segundo lugar, se encuentra África occidental y central (23 400), mientras que África oriental y meridional tiene la tercera mayor proporción de homicidios de menores de 25 años (15 000). La tasa más baja de homicidios de personas le corresponde a Europa Central y oriental y la Comunidad de Estados Independientes, seguida en orden ascendiente por oriente Medio y África septentrional (Unicef, 2014).

Según este mismo informe,

(...) los datos indican que es mucho mayor el número de niñas y niños que sufren la violencia en forma de disciplina, por lo general en sus propios hogares y desde que son muy jóvenes. Como promedio, seis de cada 10 niñas y niños del mundo (unos 1000 millones) de dos a 14 años de edad, sufren de manera periódica castigos físicos — corporales - a manos de sus cuidadores. En la mayoría de los casos, las niñas y los niños son objeto de una combinación de castigos físicos y agresiones psicológicas. En general, las formas más graves de castigo corporal, tales como, los golpes en la cabeza, las orejas y el rostro, o los golpes fuertes y reiterados, son las menos frecuentes. Como promedio, esas formas de castigo afectan al 17\% de las niñas y los niños en 58 países. En otros 23 países, la aplicación de castigos físicos severos está generalizada, con más de uno de cada cinco niñas y niños afectados (Unicef, 2014). ${ }^{2}$

Por otra parte, el hecho de que un gran número de niñas y niños sea objeto de formas violentas de disciplina parece contradecir los resultados acerca de las actitudes de los adultos con respecto a esa forma de violencia. Así, sólo tres de cada 10 adultos del mundo creen que para criar o educar de manera adecuada a una niña o un niño es necesario apelar al castigo físico. Con la excepción de Suiza, en todos los países del mundo el porcentaje de adultos encuestados que creen que el castigo físico es necesario es constantemente inferior al porcentaje de niñas y niños de dos a 14 años que son sometidas/os a formas violentas de disciplina (Unicef, 2014).

A medida que las niñas y los niños crecen, aumenta su vulnerabilidad ante otras formas de agresión, como la violencia por parte de sus padres o a manos de sus parejas íntimas. Son frecuentes, por ejemplo, las agresiones físicas entre estudiantes, especialmente entre los varones. En 25 países con datos comparables, la prevalencia de las agresiones físicas contra estudiantes de 13 a 15 años va desde un 20\% en la ex-república Yugoslava de Macedonia y el Uruguay hasta más de un 50\% Botswana, Djibouti, Egipto, Ghana, la república Unida de Tanzania (Dar es Salaam) y el Yemen. A nivel mundial, más de uno de cada tres estudiantes de 13 a 15 años de edad es objeto de por lo menos un episodio de acoso o intimidación de manera habitual (Unicef, 2014).

Tal como lo ilustra el contenido del recuadro, buena parte de la violencia ejercida contra las niñas y los niños está vinculada a las prácticas disciplinarias utilizadas por las madres y los padres en la crianza de las hijas y los hijos.

Tales prácticas son concebidas como sanciones, amonestaciones o avisos, cuyo fin es corregir alguna falta o contravención de lo estipulado por los progenitores o quienes estén a cargo de las niñas y los niños. Sin embargo, «en torno al uso de castigos existe una controversia aún no resuelta. De un lado, se argumenta que los castigos son necesarios dada la responsabilidad que tienen los adultos de orientar el comportamiento de las niñas y los niños. De otro lado, en el marco de la preocupación por preservar la integridad y el bienestar de las niñas y los niños, así como el respeto a sus derechos, se considera que los castigos son una forma de violencia, maltrato o abuso y, por lo tanto, un factor de

1 Según las estadísticas de mortalidad del Inegi, durante 2015 se registraron en México 1057 homicidios de niñas, niños y adolescentes, es decir, 2.8 homicidios cada día. Los homicidios de adolescentes entre 15 y 17 años incrementaron 3.8\% de 2014 a 2015 (Inegi, 2016).

2 Según la Encuesta Nacional de Niños, Niñas y Mujeres, realizada durante el año 2015 por el Instituto Nacional de Salud Pública y Unicef México, seis de cada 10 niñas, niños y adolescentes entre uno y 14 años reportaron haber experimentado algún método violento de disciplina infantil en sus hogares; una de cada dos niñas, niños y adolescentes reportó haber sufrido alguna agresión psicológica por algún miembro de su familia, y uno de cada 15 niños y niñas reportaron haber recibido alguna forma de castigo físico severo - jalones de orejas, bofetadas, manotazos o golpes fuertes- como método de disciplina (Instituto Nacional de Salud Pública-Unicef México, 2016). 
riesgo que puede derivar en consecuencias negativas para su desarrollo físico, social o emocional» (Aguirre, 2000, p. 21).

Pese al desarrollo de abundantes líneas de investigación sobre el maltrato infantil, sigue habiendo en nuestros días algunas deficiencias teóricas notables. Así, se carece de un concepto de maltrato infantil que sea unívoco y universalmente aceptado. Las consecuencias de este hecho son importantes, en primer lugar, porque distintos autores y autoras tildan de malos tratos cosas diferentes. Hay quienes piensan que esto no importa, pues en la práctica podemos distinguir a las claras lo que es maltrato de lo que no lo es. De acuerdo con Sanmartín, si el tema fuera tan sencillo no debería haber dificultades en responder, por ejemplo, a una cuestión tan común como la siguiente: dar un bofetón a un hijo, ¿es maltratarlo físicamente? Hay individuos partidarios de responder con un sí y partidarios del no. Incluso hay partidarios del sí que piden la penalización de la bofetada. En mi opinión, pese a que se argumenta que este tipo de actos hacen parte de la potestad que tienen los padres, madres y tutores de «corregir razonable y moderadamente» a las niñas y los niños, es muy importante aclarar qué se entiende por «corregir», excluyendo cualquier forma de violencia porque nunca se debería corregir utilizando la violencia (Sanmartín, 2008, p. 20).

Para Sanmartín, desde un punto de vista científico y moral es insostenible que el bofetón o la nalgada sean considerados «maltrato» según las circunstancias, o que estas prácticas culturalmente aceptadas deban ser vistas como un recurso «incorrecto» y no como violencia, juzgándolas violentas únicamente cuando originan una lesión importante como consecuencia de su potencia, o cuando se perpetúan como «método educativo». Desde esta perspectiva, no puede hacerse la distinción entre maltrato y violencia, pues maltratar es violentar, entendiendo por violencia contra las niñas y los niños cualquier acción u omisión que les cause o les pueda causar un daño, sin importar cuál es la intencionalidad de quien ejerce la acción. El hecho es que, más allá de que el padre o la madre que maltrata a su hija o hijo lo haga «por su bien» y no tenga la intención de dañarle sino de enmendar su conducta, puede causarle un daño.

Las formas de maltrato/violencia contra las niñas y los niños que identifica Sanmartín son las siguientes:

1. Maltrato físico: cualquier acción que tienda a causar lesiones físicas a una niña o un niño (las cause o no).

2. Abandono o negligencia: cualquier inacción (rechazo por el que se priva a la niña o al niño de la supervisión o atención esencial para su desarrollo).

3. Maltrato psicológico: cualquier acción (rechazar, ignorar, aterrorizar, aislar, presenciar violencia en la pareja, etc.) u omisión (privación de sentimientos de amor, afecto, seguridad, etc.) que tienda a agredir cognitiva o emocionalmente a una niña o a un niño.

4. Abuso sexual: cualquier acción que involucre o permita involucrar a una persona menor en actividades de tipo sexual. (Sanmartín, 2008, p. 21)

En el presente trabajo tomo como referencia general este marco conceptual con el que pretendo dar cuenta de los principales hallazgos que ha arrojado la investigación social reciente en torno a las formas y a los tipos de violencia utilizados por las madres y los padres en la crianza de las niñas y los niños en el contexto mexicano. La presentación de estos resultados se hace teniendo en cuenta las estrategias metodológicas que han sido utilizadas en la investigación empírica.

Para llevar a cabo la revisión bibliográfica busqué los artículos y textos que contuvieran informes de investigaciones. Para ello, en primera instancia, hice la consulta en la biblioteca Daniel Cosío Villegas de El Colegio de México A.C. ${ }^{3}$, y en el sistema de bibliotecas de la Universidad Nacional

3 Contiene una de las más importantes colecciones latinoamericanas en ciencias sociales y humanidades, particularmente sobre administración pública, economía, estudios internacionales, demografía, desarrollo urbano, historia, lingüística, literatura hispánica, política y sociología, y en estudios de género, traducción y el impacto social de la ciencia y la tecnología. El acervo se compone de más de 400000 títulos de libros y folletos (poco más de 700000 volúmenes) que incluyen una colección representativa de obras en idiomas de Asia, África y Medio Oriente, y cerca de 8000 títulos de publicaciones periódicas de los cuales casi 3500 se reciben regularmente. 
Autónoma de México-Unam ${ }^{4}$. En segunda instancia, consulté las siguientes bases de datos disponibles en Internet: Clase (Citas Latinoamericanas en Ciencias Sociales y Humanidades), Academic Search Complete, JSTOR, Scientific Electronic Library Online (SciELO) - México, Redalyc — Red de Revistas Científicas de América Latina y el Caribe, España y Portugal.

El procedimiento de búsqueda hizo énfasis en identificar los artículos más recientes y cubrir hacia atrás los últimos veinte años. La búsqueda comenzó por los temas más específicos vinculados a nuestro interés y luego se procedió por aproximación definiendo autores, procesos, eventos, situaciones, poblaciones, cercanas o relacionadas. Como producto de la búsqueda, selección y clasificación correspondiente, encontré más de 70 textos sobre el tema, entre artículos de revistas y capítulos de libro. Con fines analíticos propongo aquí que es posible diferenciar tres grandes vías o tendencias en la investigación social que se ha realizado sobre el tema. Tales tendencias están vinculadas «al tipo de estrategia utilizada para recabar los datos y otorgarle sentido a los mismos» (Ragin, 2007, p. 96). Así, existe una tendencia que privilegia el uso de métodos cualitativos, otra que privilegia el uso de métodos cuantitativos y una tercera en la que es utilizada, de forma complementaria, la información generada a través de encuestas, entrevistas y revisión de otras fuentes secundarias. En los siguientes apartados presento una síntesis de los estudios incluidos en cada uno de los enfoques generales; en tal síntesis tengo en cuenta el propósito de los mismos y los resultados o hallazgos más relevantes.

\section{Estudios realizados desde un enfoque cualitativo}

El trabajo realizado por el antropólogo norteamericano Oscar Lewis puede considerarse pionero en el abordaje de la violencia intrafamiliar, al adentrarse en la subjetividad y en la historia de vida de hombres y mujeres de una vecindad pobre de la ciudad de México en la segunda mitad de la década de 1950. Sus estudios en torno a las familias urbanas y rurales revelan que la violencia era un componente $\tan$ frecuente en las relaciones familiares que se consideraba «natural» o «normal». Lewis se adelantó a su tiempo, pues tendrían que pasar casi dos décadas para que en los años 70 el feminismo académico comenzara a cuestionar esta «naturalidad» y convirtiera la violencia intrafamiliar o doméstica en un objeto de investigación legítimo y especializado (González, 2006). En su obra «Los hijos de Sánchez», Lewis establece que algunas de las características de las familias que estaban inmersas en la cultura de la pobreza eran la alta incidencia del alcoholismo, el recurso frecuente a la violencia para zanjar dificultades, el uso frecuente de la violencia física en la formación de las niñas y los niños, el golpear a la esposa, la incidencia relativamente alta de abandono de la familia por los padres varones, una tendencia hacia las familias centradas en la madre y una fuerte predisposición al autoritarismo (Lewis, 1965).

Separados por un periodo de tiempo prolongado, otro estudio sobre el tema que se puede considerar pionero es el realizado por el antropólogo norteamericano Matthew Gutmann, quien examinó los significados y las prácticas de algunos hombres de la Colonia de Santo Domingo, así como la influencia que la región, la clase y la edad tenían sobre las cambiantes identidades masculinas en el México contemporáneo. Gutmann expone que «existían diferencias en las actitudes hacia la paternidad y el comportamiento de los padres en las clases alta y baja» (Gutmann, 2000, p. 110), y que no existía un solo patrón de la masculinidad. Asimismo, el autor establece que entre los hombres y las mujeres de la colonia estudiada existía una sensación generalizada de que, en lo que se refiere a la participación activa de los hombres en la paternidad-crianza, habían ocurrido cambios significativos, aunque no del todo uniformes, de una generación a otra. "Siempre hubo algunos hombres que pasaban mucho tiempo con sus niñas y niños pequeños, dirán algunos, pero hoy en día son menos excepcionales» (Gutmann, 2000, p. 112).

Las transformaciones experimentadas en el tránsito del mundo rural al urbano están ejemplificadas por los residentes de Santo Domingo provenientes de áreas rurales. Con frecuencia ellos recuerdan

$4 \quad$ Sistema que cuenta con más de 12.7 millones de libros y otros documentos impresos. 
infancias que no fueron muy satisfactorias. De manera similar, las personas que nacieron y crecieron en la ciudad de México a menudo comentaban que, durante su infancia, la vida de los hombres y las mujeres en las colonias era difícil y desigual (Gutmann, 2000, p. 105).

En cuanto a las obligaciones paternas y maternas, Gutmann pudo establecer que «en Santo Domingo había una diversidad significativa definida por cuestiones generacionales e inclinaciones individuales» (Gutmann, 2000, p. 106). Sin embargo, el mismo autor menciona que, de forma abrumadora, las personas a quienes entrevistó afirmaban que había diferencias marcadas en las obligaciones relacionadas con la crianza:

(...) los hombres debían, ante todo, sostener económicamente a la familia, mientras que se esperaba que las mujeres atendieran el hogar - lo que significaba cuidar a las niñas y los niños, al marido y la casa, con frecuencia en este orden de importancia. (Gutmann, 2000, p. 121)

Respecto a las tareas de disciplinar a las hijas e hijos, según sus informantes varones, (...) el temperamento y la conducta de los hombres estaba pasando por un proceso de cambio, de forma tal que el hecho de que demostraran más afecto hacia las niñas y los niños se consideraba algo propiamente masculino. Pocos informantes cuestionaban la idea generalizada de que los hombres son por naturaleza más pacientes o comprensivos que las mujeres, y que los padres son más «consentidores con sus hijas e hijos que las madres. En más de una ocasión le informaron al autor que «cuando andan con los 'escuincles', los hombres aguantan todo», mientras las madres hacen que se cumplan las reglas con mayor rigor que los padres, incluso cuando es preciso dar una tunda. (Gutmann, 2000, p. 125)

Los hombres de Santo Domingo le informaron a Gutmann que «les pegaban a sus hijos e hijas, de la misma manera que a ellos los abofetearon y les dieron nalgadas y cinturonazos cuando eran jóvenes; sin embargo, los castigos más violentos los llevaban a cabo las madres, situación que para los sujetos informantes era «normal» (Gutmann, 2000, p. 125).

Los testimonios recabados por el autor daban cuenta de la manera en que, con mayor regularidad que las niñas, los niños varones sufrían castigos violentos. Sin hacer precisión en los datos, Gutmann señala que «algunos de los hombres con un historial de maltrato a mujeres y niños explicaban que ellos también eran producto de fuerzas más amplias y algunos preguntaban cómo podían ser culpados por males que, claramente, eran de la sociedad» (Gutmann, 2000, p. 124). Para el autor, «el que los hombres fuesen victimarios y víctimas, fundamenta los argumentos de que la violencia masculina en México era producto de un sistema machista, mantenido tanto por mujeres como por hombres» (Gutmann, 2000, p. 125).

En esta misma línea de indagación, pero con una pretensión comparativa, es importante mencionar el estudio realizado por Olga Lorena Rojas en torno a la paternidad y la vida familiar en la Ciudad de México. La investigación de Rojas sobre el desempeño masculino en los procesos reproductivos y en la vida doméstica incorpora el tema del ejercicio cotidiano de la paternidad y la participación masculina en la crianza y el cuidado de las hijas e hijos, como una dimensión específica de la vida familiar para caracterizar dos tipos ideales de paternidad: uno tradicional y otro moderno. Para ello, la autora analiza la participación de los padres varones en el aseo, en la alimentación, y en el cuidado de las hijas y los hijos, abordando de manera específica el grado de cercanía —-física y emocional— que establecen con sus hijos e hijas, la manera en que definen y ejercen la autoridad y la manera en que les disciplinan y corrigen. Este conjunto de aspectos lo analiza la autora de tal manera que se puede dar cuenta de las diferencias, semejanzas y matices entre varones pertenecientes a diferentes grupos de edad y sector social, y según la actividad económica de sus cónyuges, en el ámbito urbano de la ciudad de México (Rojas, 2008).

La autora identifica que,

(...) los padres mayores de sectores populares se reconocen a sí mismos como padres poco cariñosos y un tanto duros con sus hijas e hijos, con los cuales prefirieron mantener una

5 En México, la palabra «escuincle» es muy usada para referirse a los niños y niñas de forma despectiva. Es un término más o menos equivalente a «mocoso» o «pelado» en Colombia. 
relación de distancia, de manera que su imagen como padres fuese respetada. La manera cotidiana de corregir y disciplinar a sus hijas e hijos, en la mayoría de los casos, consistió en el regaño enérgico además de las nalgadas y los manazos. El escaso nivel de cercanía física y emocional que esos varones tuvieron con sus hijas e hijos se explica porque consideran que el cuidado y la crianza de los mismos es una tarea de competencia femenina, sin importar que la esposa desempeñe una actividad remunerada. (Rojas, 2008, p. 152)

En cuanto a los padres mayores de sectores medios,

(...) aunque algunos de ellos consideran que es obligación de la madre hacerse cargo de la crianza y el cuidado de las hijas y los hijos, prefirieron infundir respeto y miedo en estos últimos, mientras que en otros casos dieron preferencia al convencimiento y al diálogo antes que a las reprimendas. A diferencia de la clara relación de distancia física y emocional establecida con sus hijas e hijos por la mayoría de los padres mayores de ambos sectores sociales, los padres jóvenes de sectores populares intentan vincularse de manera más cercana con sus pequeños. Sin embargo, cuando se trata de corregir a sus hijas e hijos la mayoría emplea los regaños severos y los golpes, de tal suerte que reconocen que su imagen como padres es temida por sus hijas e hijos. (Rojas, 2008, p. 158)

(...) los padres jóvenes de sectores medios se destacan por la cercanía emocional y física que han establecido con sus hijas e hijos, con quienes suelen jugar, platicar y convivir todos los días por las tardes y durante los fines de semana. Cuando corrigen los comportamientos de sus hijas e hijos, algunos de estos padres optan preferentemente por el diálogo y el convencimiento, antes de los regaños y los castigos y, ocasionalmente, las nalgadas. Si bien entre los padres jóvenes se encontraron claros signos de un mayor involucramiento en la crianza y el cuidado de las hijas e hijos, los padres jóvenes de sectores populares prefieren convivir con sus hijos en vez de con sus hijas, y recurren a los regaños fuertes e incluso a los golpes para disciplinar a su descendencia. (Rojas, 2008, p. 159)

Estas características le permitieron a la autora clasificar a los padres mayores como más cercanos al tipo ideal de paternidad tradicional y a los padres jóvenes con rasgos más cercanos o propios del tipo ideal del padre moderno.

Una de las conclusiones más relevantes de este estudio es que la paternidad entre los varones de sectores medios urbanos está experimentando importantes modificaciones en su expresión cotidiana, sobre todo en las generaciones más jóvenes de padres, puesto que en ellos se encontraron claros signos de un mayor involucramiento en la crianza y el cuidado de sus hijas e hijos.

Por último, uno de los estudios más recientes sobre el tema es el realizado por Carolina Agoff y Sara Makowski en torno a las «vivencias y experiencias de violencia de niños, niñas y jóvenes». ${ }^{6}$ El estudio está dirigido a explorar las narrativas singulares sobre la violencia que se ejerce contra la infancia a partir de los puntos de vista, experiencias y representaciones de distintos actores sociales: niñas, niños y jóvenes, maestros y maestras, padres y madres de familia y personas expertas en temas de infancia. Un primer hallazgo del estudio está relacionado con el amplio consenso y aceptación social de la violencia que ejercen los padres y madres hacia sus propias hijas e hijos como parte de la cultura familiar y como una forma «razonable» de educar. Tal como ya hice mención,

(...) la violencia física es un castigo muy extendido y abiertamente aceptado como forma de disciplinar y educar a las hijas e hijos. Si bien los padres afirman que quieren inculcarles valores a las hijas e hijos como el respeto, coinciden también en que estos últimos «les toman la medida» a los padres y no respetan los límites que ellos imponen. Las hijas e hijos los «obligan» a castigarlos de ese modo, ya que las advertencias y amenazas no bastan. (Agoff \& Makowski, 2009, p. 12)

La violencia física es parte de una cultura familiar que se transmite de generación en generación. Los padres y madres fueron educados así por sus propios ascendientes — «a palos y a gritos»—.

$6 \quad$ El trabajo hace parte del componente II del estudio sobre la violencia contra la infancia en México que se desarrollará con detalle más adelante (Agoff \& Makowski, 2009). 
No obstante, identifican ciertas diferencias respecto de generaciones anteriores: ahora no existen los castigos injustificados, todos son merecidos y a todos los precede una razón. En otras palabras, una vez los padres y madres les aplican los castigos a las hijas e hijos, dialogan con estos y les explican las causas y los motivos de los mismos.

(...) la forma más extendida de ponerle límites a las hijas e hijos y educarles es condicionándolos: se los priva de algo que les gusta o se les premia si se comportan bien. Los actores que participaron en el estudio admiten que con frecuencia este condicionamiento no funciona, y deben recurrir a la violencia física como castigo. (Agoff \& Makowski, 2009, p. 15)

Además de admitir que los castigos físicos son una forma de ejercer violencia contra las hijas y los hijos, también identifican las amenazas como una forma de violencia. Las razones principales de la violencia como castigo son las travesuras y las malas calificaciones en la escuela. En el marco de este estudio fue posible identificar las siguientes formas habituales que adquiere la violencia física, según el testimonio de los propios padres: jalar el cabello o las orejas, cachetadas, nalgadas, cinturonazos en las nalgas y pegar con varas (Agoff \& Makowski, 2009).

En cuanto a las formas o tipos de violencia según el contexto, Agoff \& Makowski encontraron que,

(...) en las comunidades indígenas, las niñas y los niños viven cotidianamente, en la casa y en la familia, formas de violencia que conservan fuertes rasgos autoritarios y de maltrato físico evidente, con notables diferenciaciones y discriminaciones entre niñas y niños. Allí parece perdurar la idea de que las hijas y los hijos son objeto y propiedad de sus padres, y de este modo el padre se siente con el derecho de ejercer violencia física. (Agoff \& Makowski, 2009, p. 23)

Otro de los hallazgos del estudio tiene que ver con aquello que las autoras denominan «la vacuidad del discurso de los derechos de la infancia»:

(...) pese a que se hace referencia por parte de las niñas y los niños a un discurso sobre sus derechos, esto no invalida la aceptación y la tolerancia que tienen hacia la violencia física que ejercen padres y familiares sobre ellos. (Agoff \& Makowski, 2009, p. 23)

(...) la violencia física es aceptada como una forma altamente normalizada de castigo, y quizás como la única vía posible de disciplina y educación. La referencia que hacen las niñas y los niños a los derechos de la infancia coexiste con la cotidianeidad de la violencia física, lo cual revela dos aspectos:

- Existe una apropiación superficial y retórica del discurso de los derechos que no logra desactivar ni frenar la persistencia de la violencia física contra la infancia como práctica natural y normal.

- Los niños y niñas no son asumidos por sus padres y familiares como sujetos de derecho, sino como objetos de castigo. (Agoff \& Makowski, 2009, p. 32)

Otro elemento significativo a destacar es que la referencia y las apropiaciones (retóricas) que las niñas, los niños y los jóvenes hacen del discurso de los derechos de la infancia es vivido por los maestros y padres de familia como algo amenazador, que cuestiona su autoridad y su capacidad para ejercer el control sobre sus hijas e hijos o alumnos (Agoff \& Makowski, 2009).

En relación con el discurso garantista de los derechos de la infancia, y en concordancia con estudios previos, Agoff y Makowski concluyen que,

(...) en México existe una brecha profunda entre una retórica construida a partir del discurso de la protección a los derechos de la infancia, y una práctica que sistemáticamente es violatoria de los derechos humanos y de la dignidad de las niñas, niños y jóvenes. (Agoff \& Makowski, 2009, p. 40)

Como hemos visto hasta aquí, los estudios incluidos en este enfoque coinciden en entender la violencia física como un recurso extendido y abiertamente aceptado por los padres y las madres para disciplinar y educar a las hijas y a los hijos. Con el propósito de «corregir» las conductas de las 
hijas y los hijos, las madres y los padres optan, usualmente, por las nalgadas, los cinturonazos, las cachetadas, los golpes con varas y los regaños enérgicos. Pese a esto, las autoras y autores identifican algunas diferencias importantes respecto a las actitudes hacia la paternidad y en el comportamiento de los padres varones según el sector social y la generación a la que correspondan. Así, es claro que los padres varones de sectores populares tienden a reproducir patrones tradicionales respecto a la menor cercanía que tienen con las hijas y los hijos, y respecto al uso de castigos físicos como estrategia para disciplinarles.

En contraste, en los padres y madres jóvenes y de sector medio parecen presentarse cambios importantes respecto a su actitud de mayor cercanía con las hijas y los hijos, y a su mayor involucramiento en las labores reproductivas y en el uso de estrategias distintas a la violencia para corregir sus conductas. Con relación a esto último, llama la atención que en este conjunto de estudios se hiciera referencia al uso creciente de estrategias tales como el diálogo, el convencimiento y los premios o recompensas. Pese a que los padres y madres de sectores populares también recurren al diálogo con las hijas y los hijos, este es utilizado como un recurso para justificar los castigos físicos que les aplican.

Este conjunto de estudios también hace contribuciones importantes en la investigación sobre el tema, al explorar los motivos de los castigos, las formas y tipos de violencia según el contexto, y las diferencias existentes en los castigos aplicados por los padres y madres, según el sexo de las niñas y los niños.

\section{Estudios realizados desde un enfoque cuantitativo}

Ahora bien, desde el punto de vista de este enfoque, la característica más relevante de la investigación empírica en torno al uso de la violencia física en las prácticas de crianza de las niñas y los niños es que ha predominado la perspectiva epidemiológica de carácter clínico y psicológica. Como se podrá observar en este apartado, en el primer caso una parte de los estudios ha hecho énfasis en la medición de la prevalencia o magnitud de la violencia contra los menores (Barcelata \& Álvarez, 2005; Pinheiro, 2006; Speizer, Samandari, \& Kim, 2008; Valdez, Híjar, Rojas, Ávila, \& Arenas, 2013; Valdez, Juárez, Agoff, Ávila, \& Híjar, 2006; Weber, Prado, Viezzer, \& Brandenburg, 2004). En el segundo caso, otra parte de los estudios da cuenta de la existencia de una tradición de investigación sobre la materia, enfocada con perspectiva médica, la cual se inició en México desde la década de los setenta (Híjar, Tapia, \& Rascon, 1994; Loredo, 2000). ${ }^{7}$

En el tercer caso, los estudios se han preocupado por analizar la violencia (física o sexual) experimentada por los individuos en la infancia y en la adolescencia como factor interviniente en otros procesos de la vida adulta, esto es como variable correlacionada con fenómenos, tales como, los riesgos de adquirir problemas mentales, el intento de suicidio, las adicciones, los logros educativos, la participación en el mercado laboral y la violencia de pareja (Castro \& Frías, 2010, p. 207; Frías \& Castro, 2011, p. 498; Morales, Martínez, Nieto, \& Mandujano, 2017; Rivera, Betania, Chávez, \& Ávila, 2006; Sauceda, Gutiérrez, Gutiérrez, \& Maldonado, 2006; Seixas, Bordin, Green, \& Hoven, 2009); Rivera, Betania, Chávez, \& Ávila, 2006).

Por último, hay estudios importantes sobre algunas de las manifestaciones de la violencia contra las niñas y los niños impulsados por organismos oficiales o por instituciones internacionales (Azaola, 2000).

El problema de la violencia intrafamiliar en el contexto mexicano se comenzó a explorar por medio de encuestas nacionales a partir de la década del 2000. En algunos casos se trata de encuestas

$7 \quad$ Para una revisión detallada de esta línea de investigación, ver: Loredo, Casas, Navarro, Villanueva, \& García (2016); Loredo, Casas, Figueroa, \& Vargas (2016); Loredo (2016); Loredo, Casas, \& Monroy (2014); Loredo, Casas, \& Monroy (2013); Trejo, Loredo, \& Orozco (2011); Loredo, Trejo, \& Melquiades (2011); Loredo, Trejo, García, Portillo, López, \& Capistrán (2011); Loredo, Trejo, \& Cartilla (2003); Loredo, Monter, Escudero, \& De la Teja (2003); Loredo (1999); Loredo, Trejo, Bustos, Sánchez, \& Moreno (1998); Loredo (1996); Loredo, Sierra, \& Oldak (1991); Loredo, Reynés, \& Martínez (1986); Martín, \& Loredo (2010); Perea, \& Loredo (2004); Perea, Loredo, \& Trejo (2001); Loredo (2000). 
orientadas de manera específica a estimar la violencia intrafamiliar contra las niñas y los niños, como es el caso de la Encuesta de Maltrato Infantil y Adolescente (EMIyA). En otros casos, se trata de encuestas cuyo propósito es medir otras formas de violencia — por ejemplo, violencia contra las mujeres - , pero que incluyen como variables independientes la violencia experimentada en la infancia y la violencia que los padres ejercen contra las hijas y los hijos. ${ }^{8}$ Un tercer tipo de encuestas tienen como propósito estudiar la dinámica familiar en su conjunto, por lo que incluyen apenas unas cuantas preguntas sobre violencia intrafamiliar contra las niñas y los niños. ${ }^{9}$

Las encuestas permiten, entre otras cosas: a) hacer estimaciones muy precisas sobre la magnitud y extensión de las formas de violencia contra las niñas y los niños en la zona o región que represente la muestra seleccionada; b) hacer investigaciones sobre las variables de orden contextual, sociodemográfico y de otros tipos que se asocian a la violencia contra la infancia; c) estimar los riesgos diferenciales que tienen las niñas y los niños de sufrir violencia y de que se ejerza violencia contra ellas y ellos, a partir de grupos y tipologías construidas con las variables de la propia encuesta (Casique, 2009; Castro \& Frías, 2010; Frías \& Castro, 2011; Frías \& Castro, 2013; Villatoro, Quiroz, Gutiérrez, Díaz, \& Amador, 2006).

Así, uno de los primeros hallazgos en torno a la violencia en la infancia, que se obtuvo al comparar la información obtenida mediante las tres encuestas nacionales sobre la dinámica de las relaciones en los hogares, Endireh (Instituto Nacional de Mujeres \& Instituto Nacional de Estadística, Geografía e Informática, 2004; Instituto Nacional de Mujeres \& Instituto Nacional de Estadística, Geografía e Informática, 2007; Instituto Nacional de Mujeres \& Instituto Nacional de Estadística, Geografía e Informática, 2012), es que alrededor del 40\% de las mujeres adultas reportaron haber sufrido violencia física a manos de sus padres. ${ }^{10}$ Asimismo, entre el $55 \%$ y el $62 \%$ de las niñas y los niños señalaron haber sufrido ese mismo tipo de violencia en algún momento de sus vidas (Instituto Nacional de Mujeres, 2004, 2007 y 2012).

(...) en todas las encuestas es consistente el hallazgo de que las madres están en mayor riesgo de ejercer violencia física con las hijas y los hijos, ${ }^{11}$ probablemente porque la crianza está socialmente asignada preponderantemente a ellas y por lo mismo, ellas pasan mayor tiempo con las hijas e hijos. También el número de residentes en el hogar se correlaciona positivamente con el riesgo de que se ejerza violencia contra las niñas y los niños. Otra variable claramente relacionada es la existencia de otras formas de violencia, bien sea entre los padres ${ }^{12}$, o bien en la escuela entre los pares. (Castro \& Frías, 2010, p. 226)

$8 \quad$ Tal es el caso de la Encuesta Nacional sobre la Dinámica de las Relaciones en los Hogares-Endireh 2003 (Instituto Nacional de Mujeres \& Instituto Nacional de Estadística, Geografía e Informática. (2004) y la Encuesta Nacional de Violencia contra las Mujeres Usuarias de Servicios Públicos de Salud (Envim) (Instituto Nacional de Salud Pública, 2006).

9 Tal como la Encuesta Nacional sobre la Dinámica de las Familias (Endifam) (Instituto de Investigaciones Sociales-Unam, 2005).

10 La información suministrada por la Encuesta Nacional sobre la Dinámica de las Relaciones en los Hogares 2011 (Endireh) permite establecer que el porcentaje de mujeres unidas que reportó haber sufrido directamente violencia física en su infancia por parte de las personas que las cuidaban, se mantuvo relativamente estable, apenas con una ligera tendencia al descenso que probablemente no sea significativa $(38,6 \%)($ Casique \& Castro, 2012, p. 216).

11 La Endireh 2011 permitió establecer que el 27,3\% de las mujeres unidas ejerce violencia física contra sus hijos e hijas, mientras que sus parejas no (Casique \& Castro, 2012, p. 222).

12 Es importante destacar el trabajo que en esta línea de investigación ha desarrollado Irene Casique, quien ha indagado, a partir de la información proveniente de la Endireh 2003, si ¿es en los hogares donde hay violencia conyugal hacia la mujer en los que se presenta mayor número de casos de abuso físico hacia las hijas y los hijos?, ¿proviene la violencia contra las niñas y los niños del esposo-padre golpeador?, ¿o proviene de la mujer golpeada que se constituye a su vez en madre golpeadora? Por otra parte, y más allá de las características del hombre abusador y de la mujer abusada, atendiendo a características más generales de ambos y del hogar, la autora se pregunta ¿cuáles son los factores de riesgo del abuso físico de las niñas y los niños por sus padres y madres en el caso de México? Casique identifica que la prevalencia del abuso físico por parte de padres y madres es diferente, siendo más frecuente el abuso físico materno. Asimismo, identifica algunas diferencias en cuanto a los factores que detonan el abuso físico por parte de uno u otro. Si bien se evidencia un mayor riesgo de violencia física hacia las hijas y los hijos tanto del padre como de la madre cuando existe violencia emocional del hombre contra la mujer, y mayor riesgo de violencia de ambos cuando hay violencia emocional y física hacia la mujer, los valores de riesgo asociados a estas condiciones de violencia conyugal no las señalan como los elementos predictivos más importantes de la violencia contra las hijas y los hijos, papel que más bien jugarían las condiciones familiares y culturales (Casique, 2009, p. 31). 
En coincidencia con los resultados de los estudios llevados a cabo desde el enfoque cualitativo, los datos que arrojan las encuestas muestran que el ejercicio de castigos físicos contra las hijas y los hijos es una práctica relativamente naturalizada y normalizada en la sociedad mexicana. Para Castro y Frías, «esta aceptación puede asociarse al hecho de que se la percibe como una práctica «virtuosa» destinada a corregir y educar a las hijas y a los hijos» (Castro \& Frías, 2010, p. 226).

De acuerdo con los resultados de la Encuesta Nacional sobre la Dinámica de las Relaciones en los Hogares 2003 (Endireh), diversas variables se asocian al uso de castigos físicos contra las hijas y los hijos. Entre ellas destacan la composición del hogar por sexo - los hogares extensos presentan mayor riesgo - , la edad de las hijas y de los hijos — los hogares con hijas e hijos entre los 2 y los 5 años de edad están en mayor riesgo-- el nivel educativo y el nivel socioeconómico del padre y de la madre —en ambos casos a menor nivel mayor riesgo-, la condición de trabajo de la mujer — los hogares donde la mujer trabaja fuera del hogar tienen menor riesgo- y el número promedio de niños y niñas en el hogar - mientras más alto, más riesgo- (Castro \& Frías, 2010). ${ }^{13}$

Castro y Frías también consideran que los resultados de esta encuesta ofrecen elementos para demostrar el alcance de la transmisión intergeneracional de la violencia al vincular el hecho de haber sufrido violencia en la infancia con el riesgo de ejercerla contra los propios hijos e hijas. ${ }^{14}$ En esta perspectiva, los datos permiten establecer que solo un tercio de las mujeres representadas por la Endireh 2003 ha llevado una vida relativamente libre de violencia. ${ }^{15}$ Los dos tercios restantes atestiguaron violencia entre su padre y su madre, o sufrieron castigos físicos durante la infancia, ${ }^{16}$ o ejercen violencia contra sus hijas e hijos. ${ }^{17}$ En consecuencia, «la violencia es constitutiva de la

13 En un texto reciente, Frías y Castro (2014) examinan los factores asociados al ejercicio de la violencia contra las hijas y los hijos. Adicional a los factores mencionados aquí, los coeficientes de análisis revelan que los hijos y las hijas de las mujeres divorciadas y separadas tienen un riesgo relativamente mayor de ser objeto de violencia física — con independencia de que esta la origine el padre o la madre—, que las hijas y los hijos de las casadas $32 \%$ y $34 \%$ respectivamente. En cambio, las mujeres unidas y las que hablan una lengua indígena tienen un riesgo relativamente menor de reportar que ellas o su marido ejercen violencia física contra sus hijas e hijos - $8 \%$ y $19 \%$ respectivamente - que las que indicaron no hablar una lengua indígena. A medida que aumenta la edad de la mujer y su estrato socioeconómico, el riesgo relativo de que sus hijas o hijos sean objeto de violencia física disminuye. Las mujeres que viven en zonas urbanas presentan un riesgo marginalmente mayor de indicar que sus hijos e hijas son objeto de violencia física, que las que residen en zonas rurales (p. 288).

14 La teoría de la transmisión intergeneracional de la violencia se fundamenta en los procesos de aprendizaje social, y sostiene que los patrones dominantes de interacción y los modelos de convivencia y solución de conflictos que se observan en la familia de origen, constituyen un principio activo fundamental en el desarrollo de los riesgos que tienen los individuos de ser agresores o víctimas en edades posteriores.

15 Los resultados de la Endireh 2011 permitieron confirmar la relación establecida entre haber sufrido violencia en la infancia y ejercerla ahora contra las hijas y los hijos. En las tres formas en que existe información para esta variable — haber sufrido violencia física, haber atestiguado violencia física entre los individuos mayores que la cuidaban, o haber sufrido otras formas de violencia emocional— es mayor la proporción de mujeres que ejercen violencia contra sus hijas e hijos de manera exclusiva, o la ejercen conjuntamente con sus parejas, o sus parejas la ejercen de manera exclusiva, que aquellas que no sufrieron violencia en la infancia (Casique \& Castro, 2012).

16 De acuerdo con la Endireh 2011, el 31,7\% de las mujeres unidas - 32,6\% si también se incluye a las mujeres alguna vez unidas - fue testigo de violencia física durante su infancia entre las personas adultas que la cuidaban, lo que constituye una forma de sufrir violencia emocional. Llama la atención que el porcentaje de mujeres que reportó haber atestiguado violencia en su familia de origen ha ido creciendo. De acuerdo con la Endireh 2003, fue de 24,2\%; en la de 2006 fue de 27,4\%, mientras que en la Endireh 2011 se incrementó a 31,7\%. A efectos de profundizar en este tema, se realizó un análisis descriptivo por grupos decenales de edad y se encontró que, invariablemente, encuesta tras encuesta, se produjo un incremento en el porcentaje de mujeres que reportan haber atestiguado golpes en su familia de origen en todos los grupos de edad. Este incremento es mucho mayor entre las mujeres de 75 años y más. Si bien sólo el 11,5\% de las casadas o unidas lo reportó en la Endireh 2003 , más de una de cada cuatro $(27,4 \%)$ lo indicó en la de 2011. Más aún, a medida que aumenta la edad de las mujeres en el momento del levantamiento de la encuesta, tiende a incrementarse el porcentaje de aquellas que dijeron haber atestiguado violencia en su familia de origen. De manera consistente con lo anterior, el porcentaje de mujeres unidas o casadas que reporta haber sufrido violencia emocional en la infancia ejercida por los adultos que las cuidaban bajo la forma de insultos y humillaciones, también se ha incrementado: en la Endireh 2003 fue de 19,7\%, en la Endireh 2006 fue de 21,7\%, mientras que en la de 2011 llegó a 23,1\%. En cambio, el porcentaje de mujeres unidas que reporta haber sufrido violencia física durante su infancia por las personas que las cuidaban se ha mantenido relativamente estable, apenas con una ligera tendencia al descenso, que probablemente no sea significativa: las Endireh 2003, 2006 y 2011 reportaron 4,1\%, 39,4\% y 38,6\%, respectivamente. Entre las mujeres alguna vez unidas, los porcentajes son idénticos (39,6\%). En cuanto a la distribución según la edad de la violencia física y emocional durante la infancia de las mujeres casadas o unidas, según la Endireh 2011, se puede apreciar que, para ambos tipos de violencia, la prevalencia es menor entre las mujeres más jóvenes y se incrementa al aumentar la edad. En el caso de la violencia emocional, la tendencia es constante hasta alcanzar el porcentaje más elevado en el grupo de mayor edad — 75 años y más-. En el caso de la violencia física, la prevalencia se incrementa sistemáticamente hasta llegar al grupo de 45 a 54 años, para luego presentar un cierto descenso en los grupos de mayor edad. El hecho de que las prevalencias se incrementen al aumentar la edad puede sugerir que anteriormente había más violencia de este tipo contra las niñas, y que al paso de los años estas formas de abuso han ido disminuyendo (Frías \& Castro, 2014, p. 269).

17 De hecho, los autores van más allá en otro artículo publicado recientemente, al proponer un modelo analítico que les permite demostrar la relevancia de la llamada transmisión intergeneracional e intercontextual de la violencia en México, analizando la violencia física que se sufre y ejerce en sucesivos momentos clave del ciclo de vida, entre la infancia y la crianza de hijas e hijos, pasando por la adolescencia y el noviazgo 
experiencia cotidiana de $66 \%$ de las familias, dato que revela la enorme y compleja tarea que ha de enfrentar la sociedad en esta materia» (Castro \& Frías, 2010, p. 227).

Otro estudio que es importante mencionar aquí es el llevado a cabo por Jorge Villatoro y su equipo del Instituto Nacional de Psiquiatría Ramón de la Fuente. En este estudio fueron presentados los resultados de la Encuesta de Maltrato Infantil y Factores Asociados realizada en el año 2006. La encuesta fue aplicada en escuelas secundarias públicas y privadas, rurales y urbanas, de cuatro entidades de la república mexicana, a saber, Baja California, Sonora, Tlaxcala y Yucatán, e incluyó preguntas respecto a los cuatro tipos de maltrato definidos por la Organización Panamericana de la Salud: maltrato físico, abuso sexual, maltrato emocional y descuido o negligencia (Villatoro et al., 2006). Los resultados de la encuesta mostraron que el maltrato emocional era el que más se presentaba, tanto para hombres como para mujeres, seguido por el maltrato físico.

Un aspecto a destacar es la dificultad que supone que en estas encuestas no se incluyera preguntas respecto a la severidad de los castigos o de la violencia atestiguada o sufrida directamente en la infancia, ni sobre la severidad de los castigos que como padres y madres pudiesen estar ejerciendo con sus hijas o hijos. Para Castro y Frías, «con toda probabilidad los casos reportados se refieren a lo que en la literatura se identifica como "castigo físico", es decir, nalgadas, coscorrones, bofetadas $\mathrm{u}$ otros golpes similares». ${ }^{18}$ De la misma forma, recomiendan estudiar las características del castigo físico y entenderlo como un componente central de la violencia intrafamiliar ${ }^{19}$ (Castro \& Frías, 2010, p. 210).

Respecto a esto último, los autores mencionan que el examen de otras formas de violencia contra las niñas y los niños, como la violencia sexual, la violencia emocional, y la negligencia, ha quedado en un segundo plano (Frías \& Castro, 2014, p. 264).

Otras dificultades o limitaciones de las encuestas están vinculadas a los siguientes aspectos: a) no existe un marco conceptual unificado, ${ }^{20}$ ni escalas debidamente validadas que permitan hacer mediciones sobre la violencia comparables a nivel nacional e internacional; b) las encuestas varían entre sí en términos del alcance de su marco muestral ${ }^{21}$ —el cual suele estar en función de los recursos

(Frías \& Castro, 2011, pp. 497-550; Vázquez \& Castro, 2008). De acuerdo con la Endireh 2011, las mujeres que reportaron haber sufrido violencia física durante la infancia tienen un riesgo $115 \%$ mayor de reportar que la ejercen contra sus hijos e hijas, que aquellas que no la sufrieron; este riesgo es 9\% mayor para las que indicaron que padecieron insultos o humillaciones durante la infancia, y $16 \%$ mayor para las que atestiguaron violencia física en su familia de origen. Pese a esto, es importante tener en cuenta que, según esta encuesta, el 57,7\% de las mujeres unidas o casadas, o alguna vez unidas, indicaron no tener hijos o hijas, o que estos ya eran grandes, o no contestaron las preguntas relacionadas con el posible uso de la violencia en contra de sus hijas o hijos. Es decir, tenemos una submuestra integrada por $42,83 \%$ de mujeres que tienen hijos o hijas y que respondieron a estas preguntas en la Endireh 2011. Con base en la Endireh 2011, entre las mujeres unidas o casadas, que tienen hijos e hijas y que contestaron la pregunta, $27,3 \%$ ejerce violencia física en contra de ellos, mientras que su pareja no. A la inversa, en el 2,8\% de los casos es la pareja la que ejerce este tipo de violencia contra los hijos, y la mujer no; y en el 18,5\% de los casos, ambos ejercen violencia física contra los hijos e hijas. Estos porcentajes son similares si también consideramos a las mujeres separadas, divorciadas y viudas. Estos datos deben interpretarse teniendo en cuenta que sobre las mujeres recae la mayoría de las responsabilidades de crianza y cuidado de las hijas e hijos. Es decir, su tiempo de convivencia con los hijos e hijas es mucho mayor que el de sus parejas o el de los padres de los niños y niñas, lo que incrementa el riesgo de que las madres ejerzan, en mayor medida que los padres, violencia física contra ellos. Al comparar las Endireh 2003 y 2011 , se advierte que la proporción de mujeres casadas o unidas que en 2011 declaran que ni ella ni su pareja ejercen violencia física contra sus hijos e hijas, es de $51,5 \%$ vs. $48,4 \%$ en 2003 . Se aprecia también una disminución de los casos en que solo la mujer o solo la pareja ejerce violencia contra los hijos e hijas, respecto a 2003, con un incremento de parejas en las cuales la mujer reportó que ambos ejercen violencia física contra los hijos e hijas - 16,2\% en 2003 vs. $18,5 \%$ en 2011 - (Frías \& Castro, 2014, p. 290).

18 Respecto a esto precisan que en la literatura sobre esta materia se distingue claramente el abuso físico del castigo físico. La investigación respecto al problema comenzó centrándose en el abuso físico; sin embargo, en años recientes se ha advertido la importancia de estudiar también el castigo físico (aun el que se ejerce con fines «educativos»), toda vez que la diferencia entre el abuso y el castigo físico contra las niñas y los niños es ante todo una cuestión de grados de severidad.

19 Cabe mencionar que Castro, Casique y Frías desarrollan el análisis de los resultados de las diversas encuestas que utilizan en sus investigaciones sobre el tema, a partir de considerar los distintos tipos de violencia contra las mujeres y contra las niñas y niños como producto de un contexto — patriarcal — de desigualdad de género socialmente construido tanto a nivel estructural como ideológico. Así, las manifestaciones de violencia en contra de las mujeres y las niñas y los niños, son contingentes a los patriarcados regionales en México, y esto podría explicar la distribución heterogénea de la violencia en el territorio, así como que ciertas mujeres o niñas y niños presenten un mayor riesgo de ser objeto de determinadas formas de violencia debido al contexto en el que se encuentran. También asumen la perspectiva feminista interseccional, según la cual los distintos sistemas de dominación/opresión como, por ejemplo, los sistemas raciales/étnicos, los sistemas de clase, el sistema sexual, así como el patriarcado, contribuyen a explicar la violencia en la vida de las mujeres (Frías, 2014, p. 18; Castro \& Riquer, 2014, p. 31).

20 En las dependencias u organizaciones que las llevan a cabo.

21 Mientras algunas tienen representatividad nacional otras solo representan algunos Estados. 
financieros disponibles_-; c) algunas encuestas son de hogares, mientras que otras representan solo a cierto sector de la población; d) para algunas encuestas se ha fijado una periodicidad específica, para otras no. De acuerdo con Castro y Frías,

(...) pese a estas limitaciones y a que seguimos careciendo de información respecto a muchos aspectos específicos relacionados con este tipo de violencia, las encuestas recientes ${ }^{22}$ aportan, como se mostró en páginas anteriores, datos valiosos sobre esta problemática. (Castro \& Frías, 2010, p. 208)

Junto a las encuestas, las fuentes de información existentes en las instituciones nacionales encargadas de la materia ${ }^{23}$ tienen serios problemas conceptuales y metodológicos. De acuerdo con Castro y Frías (2009),

(...) los principales problemas que tienen los registros oficiales y que dificultan llevar a cabo las labores de prevención y erradicación de la violencia contra las niñas y los niños son: a) ausencia de definiciones y conceptos sobre violencia contra la infancia homogéneas para todo el país y que se ajusten a las definiciones recomendadas por la Organización de las Naciones Unidas; b) inexistencia de indicadores sobre la composición y la dinámica de las familias donde ocurren los episodios de violencia contra las niñas y los niños; c) la información recabada no presenta las desagregaciones necesarias - por edad, por sexo, a nivel estatal y municipal, por niveles urbano/rural, etc. - para conocer la violencia contra la infancia con la precisión que se requiere para elaborar políticas y programas de prevención adecuados; d) la falta de periodicidad con la que se recaba la información de registros institucionales; $\mathrm{y}$, e) dificultades para acceder a la información por parte de investigadores, formuladores de políticas y programas, y público en general. (Castro \& Frías, 2009, p. 20)

Otro estudio llevado a cabo desde el enfoque cuantitativo y que hace aportes relevantes al abordaje de los castigos disciplinarios ejercidos por padres y madres en la ciudad de México, es el elaborado por Brígida García y Orlandina de Oliveira en torno a las familias en el México metropolitano (2006). En esta investigación se analizaron las percepciones masculinas y femeninas sobre la dinámica intrafamiliar que específicamente se refieren a la participación de los varones en los trabajos reproductivos, la intervención de las mujeres en las decisiones familiares importantes, la libertad de movimiento de estas, la violencia doméstica en contra de ellas y de las hijas y los hijos y, finalmente, las opiniones sobre los roles socialmente asignados a hombres y mujeres (García \& Oliveira, 2006).

Las autoras analizaron los resultados de la Encuesta sobre la Dinámica Familiar en las ciudades de México y Monterrey (Dinaf), encuesta diseñada y aplicada en el año 2005 para captar la información pertinente a los propósitos de la investigación. Tales resultados permiten establecer que las diferencias entre las dos áreas metropolitanas en cuanto al derecho de los padres de pegar a las hijas y a los hijos desobedientes, son mínimas. Una de las dimensiones consideradas por las autoras para analizar las relaciones de poder a partir de la información de la Dinaf está vinculada a «la presencia de violencia en contra de las mujeres y las niñas y los niños como un mecanismo de imposición del dominio masculino cuando los controles ideológicos se debilitan» (García \& Oliveira, 2006, p. 125).

En cuanto a la violencia de los padres hacia las hijas y los hijos, «los datos de la Dinaf muestran que los insultos son la forma de violencia más frecuente, seguido por la violencia física y en muy pocos casos los padres recurren a dejarles de hablar» (García \& Oliveira, 2006, p.132). Los hombres y las mujeres entrevistadas perciben un cambio importante entre la generación de ellos y la de sus padres con respecto a la utilización de castigos violentos. En la familia de origen la violencia (entre los

22 Tales como: Encuesta Nacional sobre la Dinámica de las Relaciones en los Hogares 2003, 2006 y 2011 (Endireh), la Encuesta de Maltrato Infantil y Adolescente 2006 (EMI), la Encuesta Nacional sobre la Dinámica Familiar 2005 (Endifam), y la Encuesta Nacional de Exclusión, Intolerancia y Violencia en Escuelas Públicas de Nivel Medio Superior 2006 (Eeiv) (Secretaría de Educación Pública, 2008).

23 Las instituciones que generan información sobre violencia contra la infancia, a partir de sus registros cotidianos, son: El Sistema Integral para el Desarrollo Integral de la Familia (DIF) a través del programa de prevención al maltrato infantil (Prenam), las instituciones del sector salud - Secretaría de Salud, Instituto Mexicano del Seguro Social-IMSS y el Instituto de Seguridad y Servicios Sociales para los trabajadores estatalesIssste, las Procuradurías Estatales de Justicia y la Procuraduría General de la República, y la Secretaría del Trabajo y Previsión Social. 
padres o de estos hacia las hijas y los hijos) presentaba niveles más elevados y asumía principalmente la forma de insultos o de violencia física (García \& Oliveira, 2006).

Por otra parte, hay diferencias estadísticamente significativas entre las percepciones de los varones y las de las mujeres entrevistadas respecto a la violencia que los padres ejercen hacia sus hijas e hijos, pues ellas perciben mayor nivel de violencia que ellos. Al igual que en el caso de la violencia entre los cónyuges, el maltrato hacia las niñas y los niños es más acentuado en los sectores populares y en la ciudad de México (García \& Oliveira, 2006).

Uno de los resultados más relevantes que las autoras destacan es el hecho de que «las relaciones de las mujeres jefas de hogar con sus hijas e hijos son similares a las que prevalecen en el resto de los hogares» (García \& Oliveira, 2006, p. 135). La conclusión a la que llegan es que «la importante carga de trabajo que sobrellevan estas mujeres, su mayor poder de decisión, así como el haber estado expuestas a mayor violencia en la pareja, no se traducen en una apreciable desventaja para sus hijas e hijos» (García \& Oliveira, 2006, p. 132). Para las autoras,

(...) este hallazgo no corrobora lo que se ha dicho en la bibliografía especializada acerca de las desventajas acumuladas para quienes han vivido situaciones de violencia en su infancia. En este sentido, se ha argumentado que las mujeres que provienen de hogares violentos están propensas a casarse más jóvenes, a establecer relaciones más inestables y a estar expuestas con más frecuencia a situaciones de maltrato en sus familias de procreación. Se trataría de una acumulación de desventajas, de forma que las situaciones conflictivas en las familias de origen propiciarían, de diversas maneras, la repetición de formas violentas de actuar en las familias de procreación. A esto se aunaría el hecho de que las mujeres de sectores populares tienen mayor carga de trabajos reproductivos y la toma de decisiones en sus hogares es menos compartida. (García \& Oliveira, 2006, p. 136)

En la misma perspectiva, las autoras dedican un capítulo de la investigación a

(...) analizar la participación de los varones en la crianza y cuidado de sus hijas e hijos como parte central en el ejercicio de la paternidad, en un contexto en donde se asume que se están extendiendo los valores democráticos en la familia y se busca el logro de una mayor equidad de género. (García \& Oliveira, 2006, p. 140)

Los resultados de este estudio ofrecen elementos que «contribuyen a plantear argumentos en torno a un posible cambio generacional en la práctica de la paternidad en México y en las creencias y prácticas de disciplinamiento que utilizan los padres en la crianza de las hijas y de los hijos»» (García \& Oliveira, 2006, p.142). Una vez controlado el efecto de variables de distinto tipo, como la escolaridad, los ingresos, la residencia rural o urbana en la niñez, la posición en la estructura de parentesco, la edad de la persona menor en el hogar, el trabajo extra doméstico de la cónyuge, así como la ciudad donde se reside y las opiniones que se tienen sobre el cuidado en forma igualitaria por género, García y Oliveira identificaron que «los varones que tienen más presencia en el cuidado están en el grupo de edad adulto medio (30-39 años), en comparación con los más jóvenes o los mayores de 40 años» (García \& Oliveira, 2006, p. 143).

(...) conforme a las hipótesis planteadas por diversos estudios previos sobre un cambio generacional en la paternidad, era de esperar el resultado con respecto a los adultos mayores. Sin embargo, sorprende que los varones más jóvenes (20-29 años) que se suponía estaban a la vanguardia de las nuevas prácticas paternas no sean los más dedicados al cuidado de su prole. Los resultados conducen a plantear que una parte de los hombres que tienen sus hijas e hijos a estas edades pueden no ser los que estén más dispuestos a cambiar comportamientos tradicionales largamente establecidos, y esto confirmaría la argumentación de quienes sostienen que son lentas las transformaciones de esta índole y apuntaría al hecho de que tal vez sea necesario que los varones alcancen cierta madurez y acoplamiento familiar para que dediquen más esfuerzo al cuidado de sus hijas e hijos. (García \& Oliveira, 2006, p. 162)

En su conjunto, «estos hallazgos dan cuenta de un fenómeno de transformación complejo, con avances y resistencias, donde los grupos que se adelantan o se resisten no siempre son los esperados» (García \& Oliveira, 2006, p. 180). 
En síntesis, los estudios desarrollados bajo este enfoque han permitido identificar un conjunto de variables de índole sociodemográfico, tales como el tamaño del hogar, la edad de las hijas y de los hijos, el nivel educativo y socioeconómico de los padres y madres, y la condición laboral de la mujer, variables que se configuran en factores de riesgo de la violencia a la que están expuestas las niñas y los niños.

Los trabajos que aquí he revisado coindicen en señalar que las niñas y los niños en condiciones económicas desfavorables tienen mayor riesgo de sufrir violencia. Junto a estos factores, los textos estudiados me han permitido establecer que la existencia de otras formas de violencia — de pareja o en la escuela entre pares - también se relaciona con el mayor riesgo de sufrir violencia al que están expuestos los niños y las niñas.

En segundo lugar, los estudios también permiten establecer que son las madres quienes están en mayor riesgo de ejercer violencia contra las hijas y los hijos. Para buena parte de los autores y autoras consultados, uno de los factores que explica esta mayor «predisposición» para ejercer violencia contra las niñas y los niños, es el haber experimentado violencia en la infancia. En esta perspectiva, los datos le dan sustento a lo planteado por la teoría de la transmisión intergeneracional de la violencia. Sin embargo, para otras de las autoras incluidas aquí, el haber estado expuestas a mayor violencia en la infancia o por parte de la pareja no se traduce en la repetición de tales conductas violentas en las familias de procreación. Por último, los estudios desarrollados en el marco de este enfoque coinciden en señalar que el maltrato emocional o psicológico es el tipo de violencia que más se presenta, seguido por el maltrato físico.

\section{Estudios realizados desde un enfoque que integra métodos cualitativos y cuantitativos}

Por otra parte, uno de los pocos estudios sobre el tema desarrollados en México bajo este enfoque, es el realizado por Leñero en el año 1994. El autor se propuso obtener información actualizada y generalizable a las familias urbanas y suburbanas de la ciudad de México sobre su situación como organización social formal e informal, y en especial, en su referencia con el trato de las niñas y los niños. Asimismo, se propuso «realizar un diagnóstico del proceso de cambio ocurrido en la familia, en sus modalidades de socialización y delinear alternativas de intervención social para sugerir a los programas sobre las familias» (Leñero, 1994, p. 10). Para la realización del estudio utilizó herramientas, tales como,

(...) la consulta de documentos y de estudios previos, la realización de una encuesta sociológica hecha a una muestra representativa y limitada aproximadamente a un millar de padres de familia entrevistados, investigación de estudios de caso típicos y atípicos, en profundidad a partir de historias de vida. Finalmente, hizo uso de entrevistas con informantes clave para conocer sus percepciones respecto a la problemática familiar predominante. (Leñero, 1994, p. 184)

Entre otros resultados, el estudio permitió establecer que el cuidado de las niñas y de los niños era una atribución exclusiva de las madres. El 83\% de las mujeres informó que eran ellas quienes atendían a sus hijas e hijos. Quienes más les colaboraban con esta labor eran los abuelos —en más de la tercera parte de los casos - , lo cual permite establecer que era en las redes familiares en las que los padres de familia encontraban sus mayores apoyos. Asimismo, con la creciente participación de las mujeres en el trabajo extra doméstico empezó a cobrar importancia la guardería como institución para el cuidado cotidiano de las niñas y los niños. Sin embargo, aún era muy reducida la cantidad de familias que recurrían a esta institución. Eran las madres de clase media y alta las principales usuarias (Leñero, 1994).

En el estudio se encontró que,

(...) en la educación de las hijas y de los hijos menores los padres utilizaban diversos recursos. La educación tradicional estaba basada, en buena parte, en la prohibición y en el castigo severo, y aún en los golpes. Esto pedía a la hija o al hijo una actitud de sumisión, de 
obediencia, de no rebeldía ni contestación ante los padres. El autoritarismo familiar formaba parte de la solidez de la familia. Una familia sin jefe que asumiera el mando indiscutible era considerada una unidad débil y riesgosa. Las actitudes comprensivas frente a las hijas o los hijos eran sinónimo de dudosa educación. (Leñero, 1994, p. 112)

Para Leñero,

(...) la concepción moderna de la vida familiar en cuanto a las formas de encauzamiento y orientación de las hijas y los hijos estaban cambiando radicalmente en su idealidad teórica. El modelo de buen padre educador era totalmente diferente. El de un buen hijo «educado» también. A los padres se les pedía, más que actitud prohibitiva y represiva, o incluso «amor» forjador o paternalista (que controla protegiendo sin dejar que se desarrolle por sí mismo el menor), una actitud de comprensión, acompañamiento, amor afectivo, condescendencia y coparticipación. A la hija o al hijo, más que obediencia sumisa, lealtad ciega al padre y madre, se le empezaba a pedir, entendimiento, reflexión personal, autenticidad, lealtad consigo mismo. (Leñero, 1994, p. 103)

Sin embargo, para el autor,

(...) el proceso de cambio de valores y formas de educación a las hijas y los hijos, en una sociedad modernizada como supuestamente pretendía ser la ciudad de México, seguía un camino no del todo correspondiente al modelo teóricamente asumido en la cultura moderna. Se mostraba ambivalente en muchos sentidos, lo cual implicaba contradicciones a veces críticas, puesto que se reconocía teóricamente una pauta renovada de conducta que pretendía seguir la nueva generación, frente a las anteriores, pero en el fondo, se mantenían actitudes y conductas cotidianas que reproducían las formas tradicionales de educación familiar. (Leñero, 1994, p. 134)

La declaración formal hecha por los padres, hacia el exterior, solía reconocer, en mayor o en menor medida, pero de manera cada vez más evidente, los valores y normas que podemos identificar como sintomáticos de una moderna concepción de los derechos de las personas, incluyendo la de las niñas y de los niños frente a sus padres. Pese a esto, las actitudes y comportamientos reales mantenían aún los signos del machismo preexistente y de la inequidad formal. Así, pese a que se reconocían nuevas bases de la educación paterno-filial en cuanto a las relaciones entre padres, hijas e hijos menores, se mantenían gran parte de las normas aprendidas de las generaciones anteriores. Según la encuesta aplicada,

(...) un muy alto porcentaje de padres de familia manifestaron un sentido prohibitivo marcado. Este sistema prohibitivo establecido en la familia tiene un grado diverso de significación según la edad de las niñas y de los niños. Las prohibiciones parecen ser más justificables y necesarias cuando se trataba de niñas o niños más pequeños. Arriba de los nueve años la prohibición como sistema educativo se hacía más restrictiva y negativa. (Leñero, 1994, p. 186)

Pero la actitud represiva se perfila más claramente con el sistema y rigor de los castigos:

(...) la información obtenida resalta el predominio declarado, por un lado, de la actitud de «dar consejo sin amenazas» (82\%) y de golpear a las hijas y los hijos como castigo ante faltas graves $(63 \%)$. Pese a que estas actitudes se pudiesen considerar aparentemente opuestas, en realidad pueden interpretarse de la siguiente forma: la actitud ideal comprensiva y sabia de dar consejos, era necesariamente la justificación de la segunda, cuando fallaba el consejo. El problema que planteaban estos resultados está en saber ¿por qué fallaba el consejo? Asimismo, el sistema de castigos ambivalentes que incluía la violencia física del progenitor sobre la niña o el niño, planteaba toda una problemática de la conducta paternal - maternal enfrentada a valores modernos, pero con un aprendizaje experiencial de la educación recibida. Constituía la reserva tradicional cuando no funcionaba la buena intención «modernizada»y humanista que se consideraba un tanto ilusa o teórica. (Leñero, 1994, p. 127) 
Otra de las formas predominantes del sistema de castigo, reconocido en casi la totalidad de los casos,

(...) era el regaño fuerte, que se utilizaba como represión verbal, y que podía estar cargado de ofensa psíquica - a veces más fuerte que el mismo golpe físico - pero que en otras podía responder a un mecanismo de rompimiento condicionado y temporal de la relación afectiva. En otros casos podía significar un chantaje moral en el regaño adolorido — autocastigo moral del mismo padre-madre - mostrado ante la falta, y desilusión provocada por la hija o el hijo. (Leñero, 1994, p. 129)

En esta perspectiva, Leñero planteaba «la necesidad de evaluar el sentido del regaño en una dimensión cualitativa y tipificada según situaciones y antecedentes de la interrelación simbólica establecida entre padre-madre-hija-hijo» (Leñero, 1994, p. 134).

(...) aparecían después, con una frecuencia de la mitad de los casos, el castigo de «no ver televisión» considerado como privilegio en la mayoría de los hogares; privarles de ver a sus amigos o amigas - aislamiento-, y no dejarles salir de casa — privación de libertad a domicilio- $(60 \%$ de los casos $)$. Todos ellos significaban un sistema represivo utilizado todavía por los padres jóvenes — que se suponen más modernizados como generación-, y que a veces agravaba la situación y el recelo del menor llevando a la niña o al niño a encerrarse sobre sí mismos. (Leñero, 1994, p. 147)

\section{Conclusiones}

Tal como se ha visto hasta aquí, los estudios sobre el tema que podemos considerar «pioneros» hicieron uso de estrategias de índole cualitativa, con un impulso especial desde la antropología. Estas estrategias privilegiaban el uso de herramientas tales como la observación participante y la etnografía. En contraste, los estudios más recientes hacen uso de herramientas tales como las entrevistas semiestructuradas, las entrevistas en profundidad y los grupos de discusión. En segundo lugar, podemos observar el relativo y creciente predominio de estrategias cuantitativas en el abordaje del tema. Esta tendencia ha estado vinculada, de un lado, al interés por medir la prevalencia o magnitud de la violencia contra las personas menores y, de otro, ha estado vinculada a un interés más sociológico por analizar la violencia contra las niñas y los niños, teniendo en cuenta variables de índole sociodemográfico, su relación con otras formas de violencia, y otros procesos de la vida adulta. Para ello ha sido fundamental la existencia de encuestas nacionales que, si bien han tenido diversos propósitos, han permitido tener un panorama del problema. En tercer lugar, se evidencia la muy poca elaboración de estudios desde un enfoque mixto en el que se integren herramientas cuantitativas y cualitativas. El estudio realizado desde este enfoque da cuenta de los importantes aportes y contribuciones que tal integración hizo posible en el abordaje del tema.

Por otra parte, los estudios clasificados en los tres enfoques metodológicos presentados en este trabajo coinciden en señalar que la violencia física es uno de los principales recursos utilizados y aceptados por los padres y las madres como forma de disciplinar y educar a las hijas e hijos en el contexto mexicano. En otros estudios, es la violencia verbal y psicológica la que ocupa el primer lugar en términos de los recursos utilizados por las madres y los padres. Esto último conduce a identificar la existencia de una profunda distancia entre el discurso de los padres y madres respecto a los valores y el respeto a los derechos de las niñas y los niños, y respecto a las prácticas cotidianas en las que se continúa considerando adecuado y legítimo el uso de castigos físicos para educarles. En fin, la investigación existente sobre el tema ha hecho importantes contribuciones al explorar los motivos de los castigos, las formas y tipos de violencia según el contexto, y las diferencias existentes en los castigos aplicados por los padres y madres según el sexo de sus hijas e hijos.

Asimismo, las investigaciones han permitido analizar la manera en que algunas características demográficas, sociales y económicas de los padres y madres se configuran en factores de riesgo de la violencia a la que están expuestas las niñas y los niños. Así, los estudios realizados desde 
el enfoque cuantitativo, cuyo interés ha sido indagar el problema de la prevalencia como cuestión medular, han hecho énfasis en identificar aquellas variables que se reportan como asociadas de manera estadísticamente significativa, así como el riesgo de haber sufrido violencia física en la infancia y de ejercerla con las hijas y los hijos en la edad adulta. Las variables más frecuentemente citadas han sido el nivel socioeconómico, la escolaridad, la generación, la cohorte, el estado civil, el haber sufrido violencia durante la infancia o el haber sido testigo de ella, la condición de ocupación de la pareja y el número de hijas e hijos. Tales estudios también han permitido establecer el efecto que tienen otras formas de violencia en el hogar o en la escuela como factores de riesgo para las niñas y los niños.

Adicionalmente, los estudios que se han venido realizando han abordado el tema teniendo en cuenta el proceso de cambio de los valores y de las formas de educación de las hijas y los hijos. Respecto a esto último, algunas investigaciones nos permiten establecer que ciertos padres y madres optan crecientemente por otro tipo de estrategias para disciplinar a sus hijas e hijos, vinculadas al diálogo y al uso de premios o prohibiciones. Si bien continúan haciendo uso de los castigos físicos para corregir la conducta de las hijas e hijos - tales como las nalgadas-, esta última no es la primera estrategia por la que optan. El uso creciente del diálogo parece estar vinculado a transformaciones en las actitudes hacia la paternidad, y está correlacionado con variables tales como el sector social y la generación a la que pertenecen.

En este sentido, se ha planteado un posible cambio generacional en cuanto a las creencias y prácticas de disciplinamiento que utilizan los padres y madres con sus hijas e hijos. Mientras algunos estudios establecen que son los padres y madres jóvenes de sector medio en quienes se presentan tales cambios, otros estudios establecen que los padres y madres jóvenes continúan reproduciendo prácticas tradicionales vinculadas directamente al uso de violencia física para corregir la conducta de las niñas y de los niños. Sin embargo, estos últimos estudios no establecen con claridad a qué sector social pertenecen tales padres y madres. Todo indica que corresponde a jóvenes de sectores populares, lo que plantea diferencias importantes entre los individuos que pertenecen a la misma generación pero que difieren en cuanto al sector social de donde provienen. Entre estos padres y madres jóvenes hay una apropiación claramente diferenciada de los valores considerados «modernos».

En cuanto al abordaje de las «causas» $\mathrm{o}$ «explicaciones del uso de la violencia física para disciplinar a las hijas y los hijos, lo visto hasta aquí plantea cierto predominio de los estudios que aportan pruebas empíricas que validan la teoría de la transmisión intergeneracional de la violencia. Pese a esto, desde nuestro punto de vista algunos de los trabajos presentados aquí problematizan lo planteado por esta teoría, en la medida en que no es el haber experimentado mayores niveles de violencia en la infancia o en otras etapas de la vida lo que explicaría, «únicamente», la mayor «predisposición» para ejercerla en la edad adulta, sino que también es necesario tener en cuenta, entre otros factores, la valoración positiva que los padres y madres pueden tener de los castigos físicos como un recurso que es efectivo, que garantiza los resultados que se pretenden alcanzar en términos de corregir la conducta de las hijas y de los hijos.

Respecto a esto último, sería necesario tener en cuenta en estudios posteriores los distintos factores de mediación que pueden incidir en la forma como las experiencias de violencia son traducidas en acciones, cogniciones y emociones posteriores, en un abanico múltiple de posibilidades. «Estas van desde la utilización de la agresión como medio de resolver conflictos y diferencias y su utilización frecuente, hasta la pasividad o la evasión sistemática del conflicto» (Jimeno, 1998, p. 322).

Los estudios reseñados aquí dan cuenta de «la importante contribución hecha por el feminismo en la medida en que su esfuerzo por visibilizar la violencia doméstica o intrafamiliar permitió avanzar en la descripción de la violencia que afecta a las niñas y a los niños» (Castro \& Riquer, 2003, p. 137). En esta perspectiva, en una parte de los estudios presentados aquí, la violencia física contra las niñas y los niños ha sido concebida desde un enfoque relacional, lo que le otorga un lugar fundamental al tema de acceso y uso desigual de diversos recursos al interior del hogar. En otros términos, el análisis ha permitido dar cuenta de las situaciones o condiciones en las que ocurre la violencia contra las niñas y los niños y las relaciones de poder y de género que median entre los padres, las madres, las hijas y los hijos. 
También llama la atención el lugar que, en las investigaciones más recientes, se le ha venido otorgando a categorías sociológicas tales como la clase o el sector social, el origen étnico-racial, y la generación y cohorte.

Este conjunto de elementos nos permite establecer que en México se ha venido acumulando conocimiento nuevo en esta línea desde hace varios años, pues en los diversos estudios reseñados se ha explorado el tema en nuevas direcciones. Pese a esto, la bibliografía existente sobre el tema hace relevante continuar indagando en torno a cuestiones tales como, cuál es el significado que tienen para las madres y los padres los castigos disciplinarios que utilizan con las hijas y los hijos, qué castigos son considerados violentos, qué lugar ocupan los factores del contexto en las interpretaciones que las madres y los padres hacen de las prácticas disciplinarias a las que recurren, qué papel cumplen los valores y las emociones en las decisiones respecto a cómo castigar a las hijas e hijos, cómo valoran las experiencias de castigo disciplinario severo que experimentaron en la infancia y qué efectos tienen estas valoraciones en la propensión a utilizar los mismos castigos con las hijas y los hijos.

También es importante continuar indagando en qué medida las madres y los padres han sido influenciados por nuevas concepciones difundidas a través de diversos medios en torno a los derechos de las niñas y los niños, lo que se manifiesta en el distanciamiento o transformación de las prácticas de disciplinamiento que experimentaron en su infancia y que se utilizan usualmente con las hijas y los hijos.

\section{Lista de referencias}

Agoff, C., \& Makowski, S. (2009). Estudio sobre violencia contra la infancia en México. Componente II: una aproximación cualitativa a las vivencias y experiencias de violencia de niños, niñas y jóvenes. México, D. F.: Draft.

Aguirre, E. (2000). Socialización y prácticas de crianza. En E. Aguirre-Dávila, \& E. Durán-Strauch (Eds.), Socialización: prácticas de crianza y cuidado de la salud. Un estudio con familias y niños que inician su escolarización en Santa Fe de Bogotá, (pp. 19-92). Bogotá, D. C.: Universidad Nacional de Colombia, Facultad de Ciencias Humanas, Centro de Estudios Sociales-CES.

Azaola, E. (2000). Infancia robada: niños y niñas víctimas de explotación sexual en México. México, D. F.: Unicef, DIF, Ciesas.

Azaola, E. (2006). Maltrato, abuso y negligencia contra menores de edad. En Secretaría de Salud (Coord.), Informe Nacional sobre Violencia y Salud, (pp. 19-72). México, D. F.: SSA.

Barcelata, E., \& Álvarez, A. (2005). Patrones de interacción familiar de madres y padres generadores de violencia y maltrato infantil. Acta Colombiana de Psicología, 8(1), 35-46.

Casique, I. (2009). Violencia de pareja y violencia contra los hijos. En S. López (Coord.), Violencia de género y políticas públicas, (pp. 31-58). México, D. F.: Colef.

Casique, I., \& Castro, R. (2012). Retratos de la violencia contra las mujeres en México: análisis de resultados de la Endireh 2011. México, D. F.: Cuadernos de trabajo, 35, Inmujeres.

Castro, R., \& Frías, S. (2009). Estudio sobre violencia contra la infancia en México. Componente I. Estado del arte de los datos existentes en México sobre violencia contra niñas, niños y adolescentes. México, D. F.: Draft.

Castro, R., \& Frías, S. (2010). Violencia familiar contra la infancia en México: hallazgos a partir de la encuesta sobre dinámica en las relaciones de los hogares 2003. En S. Lerner, \& L. Melgar (Coords.), Familias en el siglo XXI: realidades diversas y políticas públicas, (pp. 217-228). México, D. F.: Unam-Pueg, El Colegio de México.

Castro, R., \& Riquer, F. (2003). La investigación sobre violencia contra las mujeres en América Latina: entre el empirismo ciego y la teoría sin datos. Cad. Saúde Pública, 19(1), 135-146. doi:10.1590/ S0102-311X2003000100015

Castro, R., \& Riquer, F. (2014). Claroscuros en el conocimiento sobre la violencia en contra de las mujeres. En I. Casique, \& R. Castro (Coords.), Expresiones y contextos de la violencia contra 
las mujeres en México. Resultados de la Endireh 2011 en comparación con sus versiones previas 2003 y 2006. México, D. F.: Instituto Nacional de las Mujeres, Universidad Nacional Autónoma de México, Centro Regional de Investigaciones Multidisciplinarias.

Frías, S. (2014). Ámbitos y formas de violencia contra mujeres y niñas: evidencias a partir de las encuestas. Acta Sociológica, (65), 11-36. doi:10.1016/S0186-6028(14)70235-X

Frías, S., \& Castro, R. (2011). Socialización y violencia: desarrollo de un modelo de extensión de la violencia interpersonal a lo largo de la vida. Revista Estudios Sociológicos, 29(86), 497-550. doi: $10.2307 / 23043405$

Frías, S., \& Castro, R. (2013). La familia y la escuela: escenarios de vulnerabilidad para los niños y niñas en México. En Y. Peña (Ed.), Discriminación y violencia. Sexualidad y situación de vulnerabilidad, (pp. 83-103). México, D. F.: Conaculta-Inah.

Frías, S., \& Castro, R. (2014). Violencia familiar en contra de las mujeres mexicanas. En I. Casique, \& R. Castro (Coords.), Expresiones y contextos de la violencia contra las mujeres en México. Resultados de la Endireh 2011 en comparación con sus versiones previas 2003 y 2006, (pp. 259-306). México, D. F.: Instituto Nacional de las Mujeres, Universidad Nacional Autónoma de México, Centro Regional de Investigaciones Multidisciplinarias.

Frías, S., \& Erviti, J. (2014). Sexual abuse of adolescents and teenagers in Mexico: Prevalence and factors associated. Child Abuse and Neglect, 38(14), 776-787. doi:10.1016/j.chiabu.2013.12.001

García, B., \& Oliveira, O. (2006). Las familias en el México metropolitano: visiones femeninas y masculinas. México, D. F.: Centro de Estudios Demográficos, Urbanos y Ambientales, Centro de Estudios Sociológicos, El Colegio de México.

Gelles, R. (2001). Child abuse-an overview. En R. E. Clark, J. Freeman, \& Ch. Adamec (Cooords.), The encyclopedia of child abuse, (pp. XI-XXIV). New York: Facts on File, Inc.

González, S. (2006). Las mujeres y la violencia doméstica en un pueblo del Valle de Toluca, 19701990. En A. De los Reyes (Comp.), Historia de la vida cotidiana en México, (pp. 341-363). México, D. F.: Siglo XX, El Colegio de México, Fondo de Cultura Económica.

Gutmann, M. (2000). Ser hombre de verdad en la ciudad de México ni macho ni mandilón. México, D. F.: Centro de Estudios Sociológicos, El Colegio de México.

Híjar, M., Tapia, T., \& Rascon, A. (1994). Mortalidad por homicidio en niños. México, 1979-1990. Salud Pública de México, (36), 529-537.

Instituto de Investigaciones Sociales-Unam. (2005). Encuesta Nacional sobre la Dinámica de las Familias en México (Endifam 2005). México, D. F.: Inegi.

Instituto Nacional de Mujeres, \& Instituto Nacional de Estadística, Geografía e Informática. (2004). Encuesta Nacional sobre la Dinámica de las Relaciones en los Hogares 2003. México, D. F.: Inegi.

Instituto Nacional de Mujeres, \& Instituto Nacional de Estadística, Geografía e Informática. (2007). Encuesta Nacional sobre la Dinámica de las Relaciones en los Hogares 2006. México, D. F.: Inegi.

Instituto Nacional de Mujeres, \& Instituto Nacional de Estadística, Geografía e Informática. (2012). Encuesta Nacional sobre la Dinámica de las Relaciones en los Hogares 2011. México, D. F.: Inegi.

Instituto Nacional de Salud Pública. (2006). Encuesta Nacional sobre Violencia contra las Mujeres (Envim). México, D. F.: Secretaría de Salud.

Instituto Nacional de Salud Pública-Unicef México. (2016). Encuesta Nacional de Niños, Niñas y Mujeres 2015. Encuesta de Indicadores Múltiples por Conglomerados 2015. Informe Final. México, D. F., México.

Jimeno, M. (1998). Corrección y respeto, amor y miedo en las experiencias de violencia. En J. Arocha, F. Cubides, \& M. Jimeno (Comps.), Las Violencias: inclusión creciente, (pp. 311-330). Bogotá, D. C.: Universidad Nacional de Colombia, Facultad de Ciencias Humanas, Centro de Estudios Sociales-CES. 
Leñero, L. (1994). Las familias en la ciudad de México: investigación social sobre la variedad de las familias, sus cambios y perspectivas de fin de siglo en el año internacional de la familia. México, D. F.: Sistema Nacional para el Desarrollo Integral de la Familia, Fondo de las Naciones Unidas para la Infancia, Centro Mexicano para la Filantropía (Cemefi), Instituto Mexicano de Estudios Sociales.

Lewis, O. (1965). Los hijos de Sánchez. Una muerte en la familia Sánchez: autobiografía de una familia mexicana. México, D. F.: Fondo de Cultura Económica (FCE).

Loredo, A. (1996). Los niños Tarahumaras. Un nuevo enfoque de maltrato al menor. El Maltrato Étnico. Boletín Médico del Hospital Infantil de México, (53), 209-210.

Loredo, A. (1999). Maltrato al menor: consideraciones clínicas sobre maltrato físico, agresión sexual y deprivación emocional. Gaceta Médica de México, 135, 611-620.

Loredo, A. (2000). Historia del maltrato infantil en México: revisión de la literatura pediátrica, Boletín Médico del Hospital Infantil de México, 58(3), 205-215.

Loredo, A. (2016). Maltrato Infantil: riesgo y prevención. México, D. F.: Editores de Textos Mexicanos.

Loredo, A., Casas, A., Figueroa, Z., \& Vargas, J. (2016). Maltrato Infantil: su estudio y manejo en el Instituto Nacional de Pediatría. México. Revista Colombia Forense, 3(1), 41-49.

Loredo, A., Casas, A., \& Monroy, D. (2013). El maltrato infantil: conceptos básicos de una patología médico social legal. Revista de la Facultad de Medicina de la Unam, 56, 5-10.

Loredo, A., Casas, A., \& Monroy, D. (2014). Maltrato infantil: características clínicas usuales. Revista de la Facultad de Medicina de la Unam, 57, 15-23.

Loredo, A., Casas, A., Navarro, P., Villanueva, H., \& García, A. (2016). Maltrato Infantil: riesgo y prevención. México, D. F.: Academia Mexicana de Pediatría.

Loredo, A., Monter, M., Escudero, A., \& De la Teja, E. (2003). Indicadores orofaciales en el síndrome del niño maltratado. Acta Pediátrica de México, 24, 240-244.

Loredo, A., Reynés, M., \& Martínez, S. (1986). El maltrato al menor. Una realidad creciente en México. Boletín Médico del Hospital Infantil de México, (43), 425-434.

Loredo, A., Sierra, J., \& Oldak, S. (1991). Síndrome de Munchausen en niños. Boletín Médico del Hospital Infantil de México, (48), 121-125.

Loredo, A., Trejo, H., Bustos, V., Sánchez,V., \& Moreno, F. (1998). Maltrato al menor: ruta de abordaje en un centro hospitalario de la ciudad de México. Acta Pediátrica de México, 19, 205-210.

Loredo, A., Trejo, J., \& Cartilla, L. (2003). Children injured: ¿Abuse or accident? Diagnosis through indicators. Boletín Médico del Hospital Infantil de México, 60, 368-379.

Loredo, A., Trejo, J., García, C., Portillo, A., López, G. E., Alcántar, M. I., .., Ortiz, S. G. (2011). Maltrato infantil: una acción interdisciplinaria en México. Consenso de la Comisión Nacional para el Estudio y Atención Integral al Niño Maltrato. Segunda parte. Salud Mental, 34, 67-73.

Loredo, A., Trejo, J., \& Melquiades, I. (2011). Síndrome del niño sacudido. Forma extrema del abuso físico infantil. Acta Pediátrica de México, (32), 177-179.

Martín, V., \& Loredo, A. (2010). Estado de nutrición en niños víctimas de abuso físico y de abuso sexual. Revista de Investigación Clínica, 62, 524-531.

Morales, S., Martínez, M., Nieto, J., \& Mandujano, J. (2017). Crianza positiva y negativa asociada a los problemas severos de conducta infantil. Health and Addictions, 17(2), 137-149. doi:10.21134/ haaj.v17i2.313

Perea, A., Loredo, A, \& Trejo, J. (2001). El maltrato al menor: propuesta de una definición integral. Boletín Médico del Hospital Infantil de México (58), 251-258.

Perea, M., \& Loredo, A. (2004). Maltrato al menor. Indicadores clínicos y sociales al maltrato físico severo. Acta Pediátrica de México, 25, 221-227.

Pinheiro, P. (2006). World Report on Violence Against Children. Ginebra: Naciones Unidas.

Ragin, C. (2007). La construcción de la investigación social. Introducción a los métodos y su diversidad. Bogotá, D. C.: Siglo del Hombre Editores, Universidad de los Andes. 
Rivera, L., Betania, A., Chávez, R., \& Ávila, L. (2006). Abuso físico y sexual durante la niñez y revictimización de las mujeres mexicanas durante la edad adulta. Salud Pública de México, 48(2), 268-278.

Rojas, O. (2008). Paternidad y vida familiar en la ciudad de México: un acercamiento cualitativo al papel desempeñado. México, D. F.: El Colegio de México, Centro de Estudios Demográficos, Urbanos y Ambientales.

Sanmartín, J. (2008). Violencia contra niños. Barcelona: Ariel.

Sauceda, G., Gutiérrez, N., Gutiérrez, J., \& Maldonado, D. (2006). El castigo físico en la crianza de los hijos. Un estudio comparativo. Boletín Médico del Hospital Infantil de México, 63(6).

Secretaría de Educación Pública. (2008). Primera encuesta nacional sobre exclusión, intolerancia y violencia en las escuelas públicas de EMS. México, D. F.: Secretaría de Educación Pública.

Seixas, D., Bordin, A., Green, R., \& Hoven, C. (2009). Measuring child exposure to violence and mental health reactions in epidemiological studies: Challenges and current issues. Ciência \& Saúde Coletiva, 14(2), 487-496.

Speizer, G., Samandari, G., \& Kim, C. (2008). Dimensions of child punishment in two Central American countries: Guatemala and El Salvador. Revista Panamericana de Salud Pública. 23(4), 247-56. doi:10.1590/S1020-49892008000400004

Trejo, J., Loredo, A., \& Orozco, J. (2011). Síndrome de Munchausen por poder en niños mexicanos: aspectos médicos, sociales, psicológicos y jurídicos. Revista de Investigación Clínica, 63, 553562.

Unicef. (2014). Hidden in plain sight. A statistical analysis of violence against children. Nueva York: Unicef.

Valdez, S., Híjar, M., Rojas, R., Ávila, L., \& Arenas, L. (2013). Prevalence and Severity of Intimate Partner Violence in Woman Living in Eight Indigenous Regions of Mexico. Social Science \& Medicine, 82, 51-57. doi:10.1016/j.socscimed.2013.01.016

Valdez, S., Juárez, N., Agoff, C., Ávila, B., \& Híjar, M. (2006). Violencia de género y otros factores asociados a la salud emocional de las usuarias del sector salud en México. Salud Pública de México, 48(2), 250-258.

Vargas, A., López, S., Zúñiga, P., Toro, G., \& Ciocca, P. (1993). Características del castigo físico infantil administrado por padres de tres colegios de Santiago. Revista Chilena de Pediatría. 64(5), 333-336. Recuperado de: http://dx.doi.org/10.4067/S0370-41061993000500003

Vázquez, V., \& Castro, R. (2008). ¿Mi novio sería capaz de matarme? Violencia en el noviazgo entre adolescentes de la Universidad Autónoma Chapingo, México. Revista Latinoamericana de Ciencias Sociales, Niñez y Juventud, 6(2), 709-738.

Villatoro, J., Quiroz, N., Gutiérrez, M., Díaz, M., \& Amador, N. (2006). ¿Cómo educamos a nuestros/ as hijos/as?: Encuesta de Maltrato Infantil y Factores Asociados 2006. México, D. F.: Instituto Nacional de las Mujeres (Inmujeres), Instituto Nacional de Psiquiatría Ramón de la Fuente Muñiz (INPRFM).

Weber, D., Prado, M., Viezzer, A., \& Brandenburg, J. (2004). Identificação de estilos parentais: o ponto de vista dos pais e dos filhos. Psicologia: Reflexão e Crítica, 17(3), 323-331. doi:10.1590/ S0102-79722004000300005 